\title{
Distributions of mixed layer properties in North Pacific water mass formation areas: comparison of Argo floats and World Ocean Atlas 2001
}

\author{
F. M. Bingham ${ }^{1}$ and T. Suga ${ }^{2,3}$ \\ ${ }^{1}$ Univ. of North Carolina Wilmington, Center for Marine Science, 5600 Marvin K. Moss Lane, Wilmington, NC 28409, USA \\ ${ }^{2}$ Tohoku Univ., Dept. of Geophysics, Graduate School of Science, Tohoku University, Aoba-ku, Sendai, 980-8578, Japan \\ ${ }^{3}$ Institute of Observational Research for Global Change, JAMSTEC, Yokosuka, Japan
}

Received: 1 December 2005 - Published in Ocean Sci. Discuss.: 28 February 2006

Revised: 1 June 2006 - Accepted: 30 June 2006 - Published: 20 July 2006

\begin{abstract}
Winter mixed layer characteristics in the North Pacific Ocean are examined and compared between Argo floats in 2006 and the World Ocean Atlas 2001 (WOA01) climatology for a series of named water masses, North Pacific Tropical Water (NPTW), Eastern Subtropical Mode Water (ESTMW), North Pacific Subtropical Mode Water (NPSTMW), Light Central Mode Water (LCMW) and Dense Central Mode Water (DCMW). The WOA01 is found to be in good agreement with the Argo data in terms of water mass volumes, average temperature-salinity (T-S) properties, and outcrop areas. The exception to this conclusion is for the central mode waters, DCMW and LCMW, whose outcropping is shown to be much more intermittent than is apparent in the WOA01 and whose T-S properties vary from what is shown in the WOA01. Distributions of mixed layer T-S properties measured by floats are examined within the outcropping areas defined by the WOA01 and show some shifting of T-S characteristics within the confines of the named water masses. In 2006, all the water masses were warmer than climatology on average, with a magnitude of about $0.5^{\circ} \mathrm{C}$. The NPTW, NPSTMW and LCMW were saltier than climatology and the ESTMW and DCMW fresher, with magnitudes of about 0.05 . In order to put these results into context, differences between Argo and WOA01 were examined over the North Pacific between 20 and $45^{\circ} \mathrm{N}$. A large-scsale warming and freshening is seen throughout this area, except for the western North Pacific, where results were more mixed.
\end{abstract}

Correspondence to: F. M. Bingham

(bigkahuna@fredbingham.com)

\section{Introduction}

Since the time of Iselin (1939), ocean scientists have been seeking to connect the distribution of water properties at the surface of the ocean to those found in the interior. Iselin noticed that interior properties were similar in temperaturesalinity (T-S) characteristics to those found at the surface. The work of Stommel (1979), Marshall et al. (1993), Huang and Qiu (1994) and Qiu and Huang (1995) and many others have laid the foundation for understanding the subduction of water from the surface ocean to where it might be observed underneath the surface sometime later. The basic result of this analysis is a subduction rate, which combines Ekman pumping and lateral induction to give a vertical mass transport into the ocean interior. While knowledge of the subduction rate can indicate how rapidly a particular water mass gets into the interior, the amount of water subducted will depend on the volume of a given water mass available, and the T-S properties of water observed in the interior depend on those at the surface when the water is subducted (Bingham et al., 2002).

Mode waters have been observed in every world ocean except the North Indian (Hanawa and Talley, 2001). They were originally given that name because they represent a mode in a volumetric census of waters classified by temperature and salinity (Masuzawa, 1969), but more recently have come to be identified by vertical minima in potential vorticity or temperature or density gradient. Mode waters are among the most important subducted water masses because they can carry climate anomalies from the surface into the interior to resurface later (Sugimoto and Hanawa, 2005). They thus provide the ocean with a memory of wintertime conditions at the surface. 


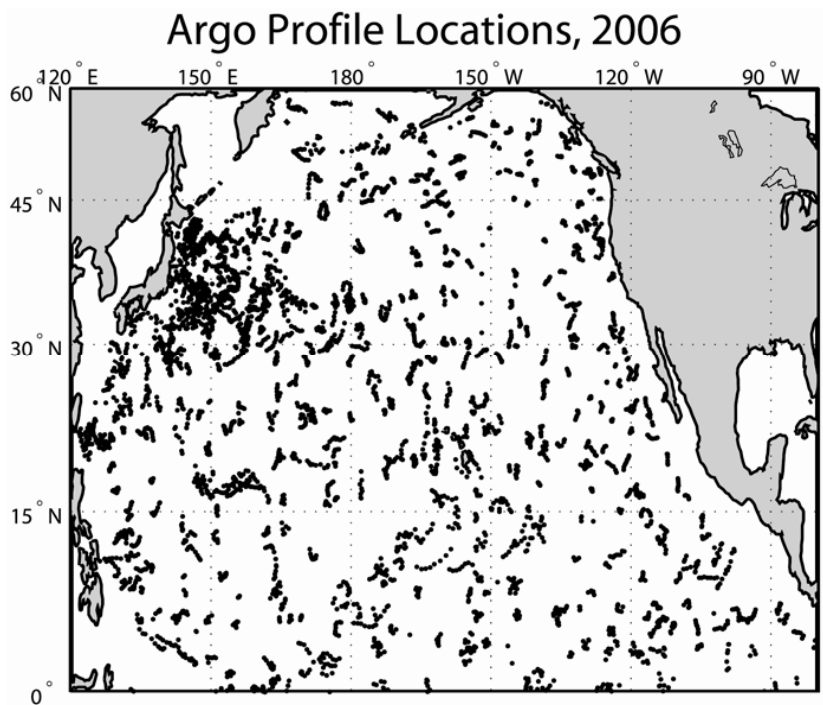

Fig. 1. Locations of 4997 Argo profiles in the indicated area in winter (January-March) 2006.

In the North Pacific, there are several varieties of mode waters (Hanawa and Talley, 2001), each with its own dynamics and formation processes. North Pacific Subtropical Mode Water (NPSTMW) is formed by strong cooling in the winter offshore of the Kuroshio and KuroshioExtension front (Bingham, 1992). North Pacific Central Mode Water has two varieties, Dense Central Mode Water (DCMW) and Light Central Mode Water (LCMW) (Oka and Suga, 2005). These waters are formed between the Kuroshio and Subpolar fronts and probably in association with eddies and other mesoscale variability (Oka and Suga, 2005; Saito, personal communication). Eastern Subtropical Mode Water (ESTMW) has temperature and salinity characteristics similar to NPSTMW, but is formed in the eastern North Pacific as a result not of strong wintertime cooling, but due to weak summer heating, and a consequent weak seasonal pycnocline (Hautala and Roemmich, 1998; Ladd and Thompson, 2000).

Another important North Pacific water mass is the North Pacific Tropical Water (NPTW; Suga et al., 2000). This water mass (which partially overlaps the ESTMW) is associated with high salinity at the surface and Ekman convergence in the middle of the subtropical gyre. It is also seen in the interior as a subsurface salinity maximum (Bingham et al., 2002).

Recently, the Argo program (Argo Science Team, 2001) has developed the ability to measure the wintertime mixed layer of the ocean to an unprecedented degree. Argo floats can profile and measure the properties at times when surface ships cannot make such measurements. Ohno et al. (2004) examined winter mixed layer depth (MLD) using Argo float data. They found that the World Ocean Atlas 2001 (WOA01; Conkright et al., 2002) MLDs generally agreed with those measured by floats, except in the northwest Pacific where the
WOA01 underestimated the MLD south of the Kuroshio Extension front and overestimated the MLD north of the front. Ohno et al. (2004) attributed the disagreement to smoothing across either the temperature/salinity front or the mixed layer front in the WOA01 as suggested by Suga et al. (2004).

Water mass formation is a crucial process in understanding and modeling ocean circulation (e.g. Xie et al., 2000) and a continuing challenge to ocean modelers (e.g. Tsujino and Yasuda, 2004; Qu et al., 2002). One of the most critical aspects of models is proper depiction of the surface mixed layer. Often, the mixed layer boundary condition relaxes to that given in some version of the World Ocean Atlas, the most current version of which was released in 2001 (Conkright et al., 2002). An important issue for ocean models is to understand how well the WOA01 and other such climatologies represent the mixed layer in terms of T-S characteristics, geographic areas and water mass volumes. Only if models have proper surface boundary conditions can the water mass formation and subduction process be accurately simulated. For that reason, the main question to be addressed in this paper is: How well does the WOA01 depict the T-S properties and outcropping regions of some of the important water masses in the North Pacific? This question will be examined by comparing the wintertime mixed layer measured by Argo floats and that depicted in the WOA01. Given the heavy smoothing done in creating the WOA01, one would expect some discrepancies as shown by Ohno et al. (2004). This study extends that of Ohno et al.. (2004) by examining water mass volumes, outcrop areas and T-S properties of several different water mass formation areas. Overall, the conclusion we will come to is that the mixed layer is depicted pretty well with respect to subtropical water masses, but less so with the central mode waters outcropping north of the Kuroshio extension.

\section{Data and methods}

Data for this study come from two sources, Argo profiles and the WOA01.

The Argo profiles we used were collected during the winter months of January-March 2006 (Fig. 1). We also examined Argo profiles from 2004 and 2005, but the data distribution is sparser. Results from these years were similar to those presented here. Each float spends 10 days between profiles. The 4997 profiles from January-March 2006 represent returns from 589 separate floats. The spatial coverage is relatively even, except for heavier sampling near the Kuroshio and some poorly sampled regions in the northwestern and western tropical Pacific. Initial data processing and quality control, described by Oka et al. $(2006)^{1}$, consist mainly of Argo's real-time quality control plus visual inspection for suspect data. MLD was calculated for each profile as the

\footnotetext{
${ }^{1}$ Oka, E., Talley, L. D., and Suga, T.: Temporal Variability of Winter Mixed Layer in the Mid- to High-Latitude North Pacific, J. Oceanogr., in review, 2006.
} 
Table 1. Winter mixed layer temperature-salinity characteristics and volumes of given water masses.

\begin{tabular}{llccccc}
\hline Name & Reference & $\begin{array}{c}\text { Sigma-t } \\
\text { Range }\end{array}$ & $\begin{array}{c}\text { Temperature } \\
\text { Range }\left({ }^{\circ} \mathrm{C}\right)\end{array}$ & $\begin{array}{c}\text { Salinity } \\
\text { Range }\end{array}$ & $\begin{array}{c}\text { WOA01 Volume } \\
\left(\mathrm{X} \mathrm{10}{ }^{14} \mathrm{~m}^{3}\right)\end{array}$ & $\begin{array}{c}\text { Argo 2006 Volume } \\
\left(\mathrm{X} \mathrm{10} 0^{14} \mathrm{~m}^{3}\right)\end{array}$ \\
\hline NPTW & Suga et al. (2000) & $23.6-25.1$ & $20.0-24.0$ & $34.9-35.5$ & 3.8 & $3.7 \pm 0.2$ \\
NPSTMW* $^{*}$ & Oka et al. (2006) & $24.5-25.9$ & $15.4-19.7$ & $34.6-35.0$ & 3.5 & $4.5 \pm 0.2$ \\
ESTMW* & Suga et al. (2004) & $23.9-26.1$ & $16.0-22.0$ & $34.6-35.4$ & 3.9 & $3.7 \pm 0.2$ \\
LCMW & Oka et al. (2006) $)^{1}$ & $25.5-26.3$ & $12.0-14.5$ & $34.3-34.6$ & 2.0 & $0.9 \pm 0.1$ \\
DCMW & Oka et al. (2006) $)^{1}$ & $25.9-26.9$ & $6.0-10.0$ & $33.7-34.2$ & 1.5 & $1.4 \pm 0.1$ \\
\hline
\end{tabular}

* ESTMW and NPSTMW overlap in characteristics, but are distinguished by geographic location. NPSTMW is taken to be west of the dateline, while ESTMW is east of it (Oka et al., 2006 ${ }^{1}$ ).

depth where sigma-t exceeds that at $10 \mathrm{~m}$ depth by 0.125 . This criterion is less strict than that recommended by de Boyer Montegut et al. (2004) (who used a criterion of 0.03 sigma-t), but similar to that determined by Kara et al. (2000) (who used a more complex criterion that approximates an isothermal depth of $0.8^{\circ} \mathrm{C}$ ). The 0.125 criterion is standard for use with the WOA01 data (e.g. Sugimoto and Hanawa, 2005) and we wished to handle the calculation of MLD consistently between the datasets we used.

We are using average MLD calculated by two different methods here. One method (method 1) uses individual Argo floats, calculates MLD from each float and then averages the MLDs. The other (method 2) takes averaged hydrographic profiles (the WOA) and calculates the MLD from those averaged profiles. De Boyer Montegut et al. (2004) have carefully considered these different methods, showing one example of how the average MLD calculated by method 2 can be less than that from method 1 . They find that globally the method 1 MLDs are $25 \%$ greater than method 2. They also suggest that method 1 may result in overestimation of the MLD when using large difference criteria like the one we use.

Mixed layer temperature (MLT) and salinity (MLS) were given for each profile as the temperature and salinity at $10 \mathrm{~m}$ depth. We present results using January-March data all treated in the same way and averaged together. There is some indication (Oka et al., 2006 ${ }^{1}$ ) that the MLD reaches a maximum in different areas of the ocean at different times of the winter. To make sure our results were not biased due to averaging the entire winter together, we re-ran all calculations in this paper using March-only Argo profiles and the March WOA01 average. The results were very similar, but with less certainty due to a smaller number of data.

In order to calculate water mass volumes, Argo MLD, MLT and MLS were interpolated onto one degree squares in the North Pacific. For a given 1 degree latitude-longitude grid point, we searched for profiles within 2 degrees of the grid point. If no profiles were found, the search radius was increased to 3 degrees, and so on up to 10 degrees. Once one or more profiles were found within a given radius, MLD,
MLT and MLS values were averaged together using a Gaussian weighting function with a 1.5 degree e-folding scale. The full 10 degree search radius was rarely used. $90 \%$ of the one degree squares had profiles within 4 degrees latitudelongitude distance of the grid point.

The WOA01 comes already averaged onto a 1 degree grid (Stephens et al., 2002; Boyer et al., 2002). We used the winter seasonal gridded profiles from the North Pacific Basin (Conkright et al., 2002), which are averaged over JanuaryMarch. MLT and MLS were given as the values at $10 \mathrm{~m}$ depth. MLD was calculated using the criterion mentioned above. This is the same calculation as that done by Suga et al. (2004).

Volumes were calculated by temperature-salinity (T-S) class in ranges of $\left(0.5^{\circ} \mathrm{C}, 0.05\right)$. For each one degree square with a particular value of temperature and salinity, the volume of that water was calculated as the surface area of the one degree square times the MLD. The total volumes for each T-S class were added up with the results presented as two dimensional volumetric censuses for both Argo 2006 and WOA01 (Fig. 2).

In the pictures of Fig. 2, what is shown is the volume assuming the T-S properties of the water are constant throughout the mixed layer. This assumption is probably true for the most part in the real ocean, where the mixed layer ends at the top of the thermocline and sigma-t increases abruptly by more than the 0.125 criterion. However, this is a somewhat problematic assumption for this calculation using the WOA01, because the mixed layer by definition changes in density between the surface and the base. It would probably be more accurate to do this volume calculation for the entire depth of the mixed layer taking vertical T-S variation into account. This problem is resolved somewhat by the choice of bin width in Figs. $2 \mathrm{a}$ and $\mathrm{b}, 0.5^{\circ} \mathrm{C}$ and 0.05 . These values give a sigma-t difference across the bin of about the same size as the mixed layer criterion of 0.125 , depending on the temperature and salinity value. Thus it is unlikely that the considerably more painstaking and error-prone calculation described would yield significantly different results. 

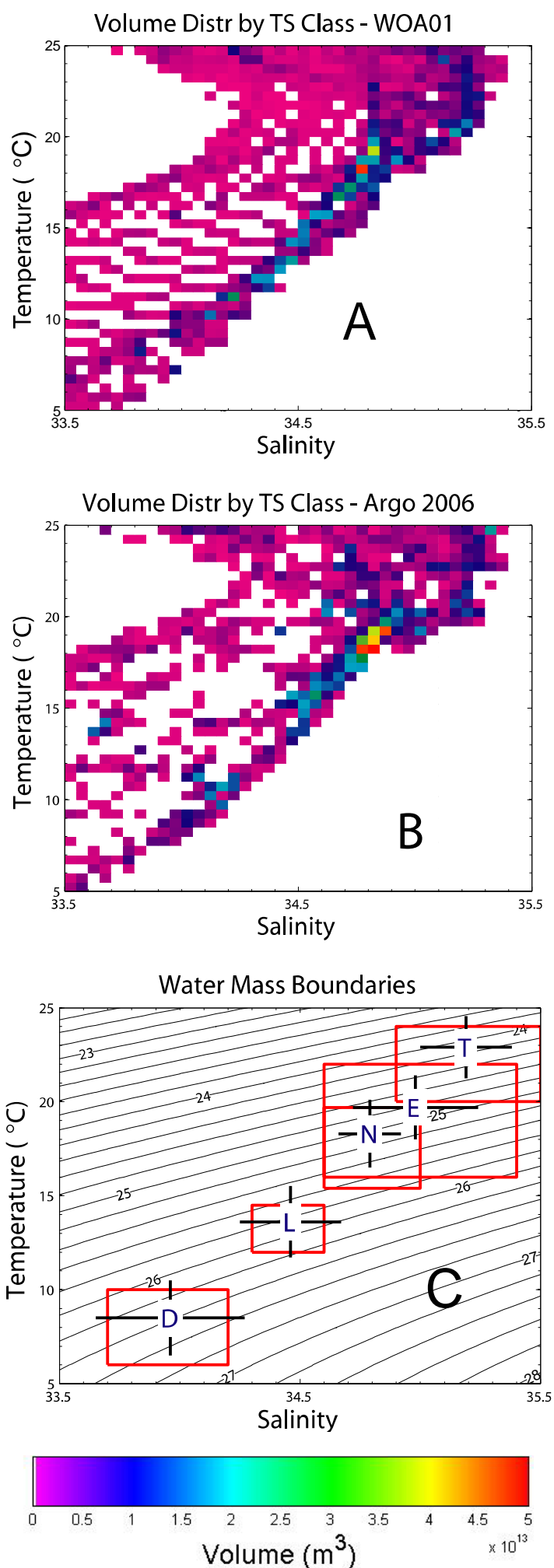

Fig. 2. (a) and (b) Distribution of water volume in the mixed layer by temperature and salinity class. Temperature and salinity are summed over ranges of $0.5^{\circ} \mathrm{C}$ and 0.05 respectively. (a) WOA01. (b) Argo 2006. (c) T-S diagram showing the boundaries of the water masses discussed in the text and shown in Table 1. Also show in are medians and standard deviations of T-S properties for Argo 2005, cases 2 and 3 in the text. The median is indicated by letters: T - NPTW; E - ESTMW; N - NPSTMW; L - LCMW; D - DCMW. Standard deviations are indicated by bars. Potential density countours are shown in panel (c). (d) Color scale for panels (a) and (b). 


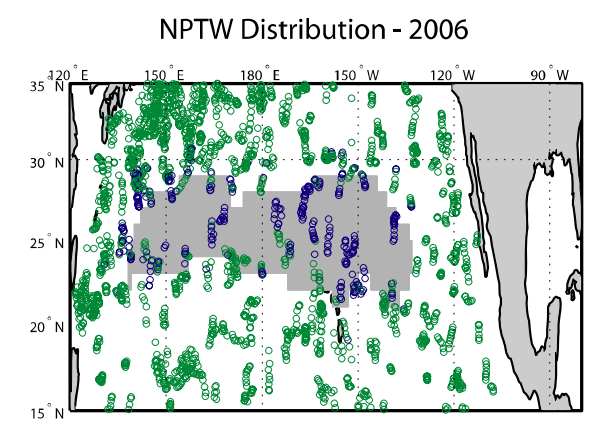

(a)

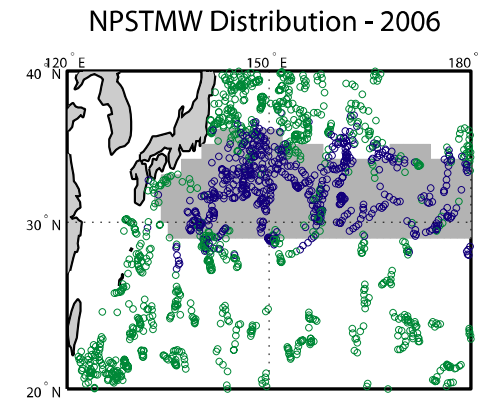

(c)
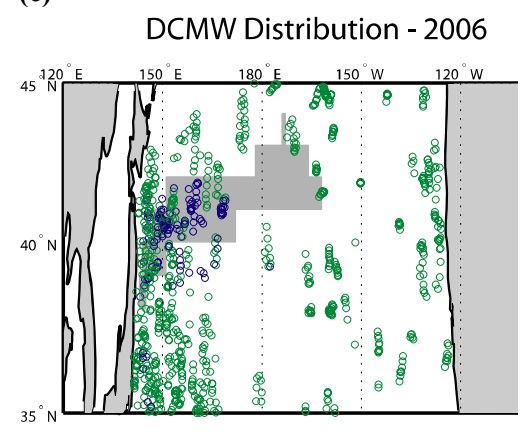

ESTMW Distribution - 2006

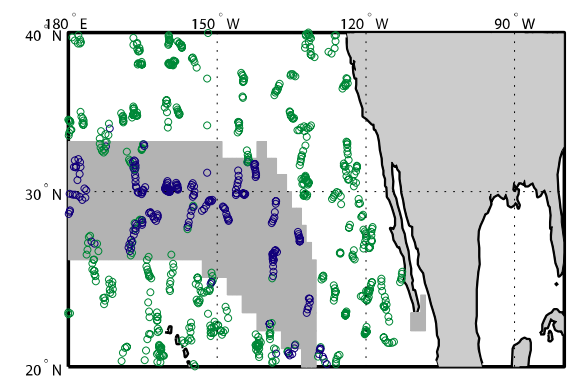

(b)

LCMW Distribution - 2006

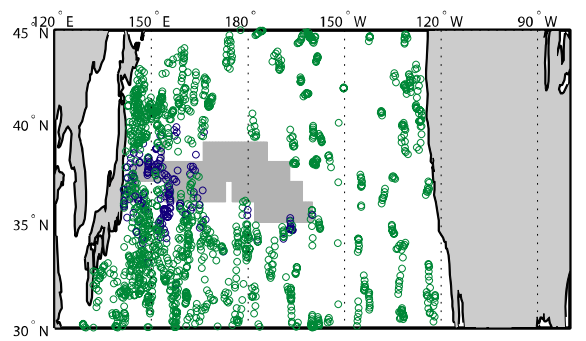

(d)

(e)

Fig. 3. Distribution of floats and various water masses in 2006. Blue (green) symbols are where floats measured properties at $10 \mathrm{~m}$ within (outside of) the range of the water mass as indicated in Table 1. Gray shaded areas are the where the $10 \mathrm{~m}$ T-S properties given in the WOA01 match the criteria for the given water mass in Table 1. (a) NPTW. (b) ESTMW. (c) NPSTMW. (d) LCMW. (e) DCMW. Note panels have different axis scaling to emphasize each water mass separately.

Another issue in Fig. 2 and Table 1 is the significance of the calculated numbers. We adopted the following procedure for calculating the significance of the volumes in Fig. 2. Since the numbers are weighted averages, we used weighted standard deviations for each one-degree square to compute a standard error, the standard deviation divided by the square root of the number of observations. Generally these standard errors were very small. If presented on the same scale as Fig. 2b, the plot would be completely white. These standard errors were added up in a "square root of the sum of the squares" sense to get total errors for the Argo 2006 volumes shown in Table 1. No such calculation could be done for the WOA01 data.

\section{Results}

The distribution of mixed layer volume from the WOA01 (Fig. 2a) reflects in part the distribution of water in the main thermocline in the subtropics, especially in the temperature range of 10 to $20^{\circ} \mathrm{C}$. A mode in volume is seen with $\mathrm{T}$ and $\mathrm{S}$ range $18-20^{\circ} \mathrm{C}$ and $34.75-34.85$. This water is the surface expression of NPSTMW. This density is somewhat lighter than classically defined NPSTMW (Masuzawa, 1969) which has characteristics of sigma-t $25.4,16.5-17.5^{\circ} \mathrm{C}$ and salinity 34.7-34.8.

There is a slight mode in volume at the density of the LCMW (14 ${ }^{\circ} \mathrm{C}, 34.5$; Fig. $\left.2 \mathrm{a}\right)$ and very little indication of DCMW as a maximum in volume at $\left(10^{\circ} \mathrm{C}, 34.1\right)$. There is a 


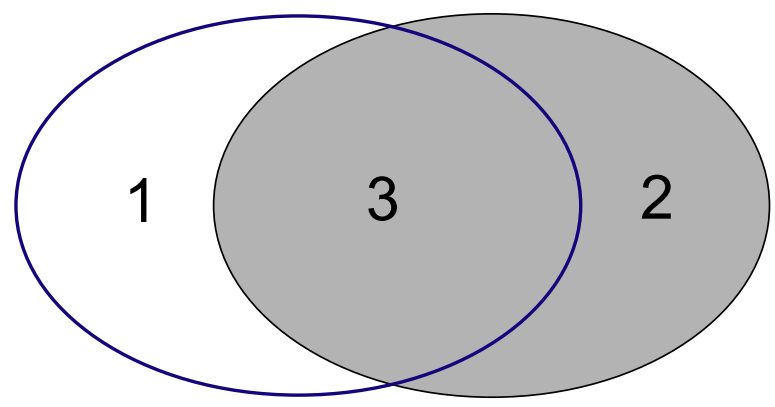

Fig. 4. Venn diagram illustrating the comparison made in Fig. 3 and Table 2. The shaded oval represents the set of floats that surfaced within the shaded areas of Fig. 3. The blue oval represents the set of floats in Fig. 3 that are colored blue, i.e. had the T-S characteristics of the given water mass. Cases as indicated in the text are shown with numbers.

small ridge representing NPTW at salinity 35.3 between 20 and $24^{\circ} \mathrm{C}$, with a small maximum at $20^{\circ} \mathrm{C}$. Not shown in this figure, but clearly visible as a mode in the T-S histogram is the dichothermal water with $\mathrm{T}<5^{\circ} \mathrm{C}$ (Miura et al., 2002; Endoh et al., 2004). It is formed in the Bering Sea and adjacent northwestern North Pacific and characterized by a subsurface temperature minimum.

The Argo 2006 data show clear delineations of most of the major water masses (Fig. 2b) with stronger and clearer peaks. NPSTMW is the most apparent peak, centered at $18-19^{\circ} \mathrm{C}$, $34.8-34.9$. There are also peaks for NPTW $\left(24^{\circ} \mathrm{C}, 35.2-\right.$ $35.3)$ and ESTMW $\left(20^{\circ} \mathrm{C}, 35.2\right)$. There is a peak at (15$\left.16^{\circ} \mathrm{C}, 34.5-34.6\right)$ that may be either light LCMW or dense NSPTWM. It does not fit exactly in the range of either as defined in Table 1. There is a volume mode that corresponds to DCMW $\left(9.5-11^{\circ} \mathrm{C}, 34.2-34.3\right)$, but is saltier and warmer than usual (Oka and Suga, 2005; Oka et al., 2006 ${ }^{1}$ ).

The most striking contrast between the WOA01 and Argo 2006 volume distributions is the water found to the fresh side of the main thermocline in the WOA01. The signal of this water is weaker in the Argo data. It reflects a tongue of cold, fresh water close the the west coast of North America (see e.g. Suga et al., 2004, Fig. 3g). In the WOA01, this tongue is spread into the interior by the averaging process and increased in volume beyond what is apparent in the Argo data.

The North Pacific Hydrobase mixed layer climatology (Suga et al., 2004) was examined in the same way, with volume calculated. It showed a distribution similar to that of the WOA01, so results are not displayed here. This implies that the Hydrobase suffers the influence of smoothing even though the purpose was to minimize this type of problem.

We now focus on some named water masses from the North Pacific, NPTW, NPSTMW, ESTMW, LCMW and DCMW. A summary of the T-S classifications and calculated total winter mixed layer volumes for each water mass are presented in Table 1 and water mass T-S boundaries are shown in Fig. 2c. In general the mixed layer volumes of the various water masses are remarkably similar between the WOA01 and Argo. This indicates that the WOA01 does a good job of depicting the volume of each water mass, but spreads that volume out somewhat in T-S space. Some discrepancies exist. For example, the NPSTMW volume is larger for Argo than for the WOA01 perhaps because Argo mixed layers are deeper for NPSTMW (Ohno et al., 2004). The LCMW volume is about 100\% larger in the WOA01 than in Argo.

Given the randomized nature of the Argo sampling, it makes sense to compare outcrop areas derived from individual profile T-S properties with those in the WOA01 for the various water masses. This is done in Fig. 3. The NPTW distribution (Fig. 3a) shows that the Argo float characteristics generally match in location with the WOA01 with the blue symbols matching the gray areas. There are some discrepancies, especially in the northwest and southeast corners of the WOA01 outcrop area and along the southern edge.

The other water masses also show general agreement between Argo and WOA outcrop areas. The water masses where the WOA01 and Argo data are most at odds are both the LCMW and DCMW (Figs. 3d and e). From Argo data, there appears to be no area of pure central mode water (CMW) outcrop. Non-CMW floats mixed up with CMW floats both inside and outside the gray areas. This is likely a result of the nature of DCMW and LCMW formation (Saito, personal communication). These water masses do not have consistent outcrops, but appear within the context of mesoscale features spun off from the Kuroshio and Oyashio extensions.

There are two types of discrepancies between float data and the WOA01 in Figs. 3a-e. One is where the float measured T-S characteristics of a particular water mass at $10 \mathrm{~m}$, but was outside of the area given by the WOA01 (case 1; blue symbol outside of gray area in Fig. 3). The other is where a float measures water properties outside that of the given water mass, but is within the area where that water mass is shown by the WOA01 (case 2; green symbol inside gray area). Finally, there is the matching case where a float is within the characteristics of a given water mass and is also within the area shown by the WOA01 (case 3; blue symbol inside gray area). These cases are more easily visualized by use of a Venn diagram in Fig. 4. Inside the oval on the right (left) is the set of floats which match the geographic area (T$\mathrm{S}$ characteristics) of a particular water mass. The intersection of the two ovals is the set of floats that match both.

To give an idea of how well the floats measure the area of the various water masses, the ratios of numbers of float profiles is shown in Table 2. In general, the floats came up with the predicted characteristics most of the time in the subtropical water masses, especially for the NPSTMW and ESTMW. The results matched less well for the central mode waters. A float measuring DCMW (LCMW) had a $49 \%$ (46\%) chance of surfacing outside of the outcrop area as defined by the WOA01. $46 \%(44 \%)$ of the floats surfacing within the outcrop area did not have DCMW (LCMW) 
Table 2. Columns 2 and 3 represent discrepancies between numbers of floats in 2006 and water properties given by the WOA01, as described in the text. Column 4 represents the matching case, the percentage of floats which matched in both geographic area and T-S characteristics.

\begin{tabular}{lccc}
\hline Name & case1/(case1+case3) $(\%)$ & case2/(case2+case3) $(\%)$ & case3/(case1 + case + case3) $(\%)$ \\
\hline NPTW & 42 & 38 & 43 \\
NPSTMW & 19 & 22 & 73 \\
ESTMW & 11 & 20 & 66 \\
LCMW & 60 & 44 & 30 \\
DCMW & 49 & 46 & 35 \\
\hline
\end{tabular}

characteristics. This tendency is mirrored in the set of matching cases in the fourth column of Table 2 showing a low percentage of matches for LCMW and DCMW, but a high percentage for ESTMW and NPSTMW. These discrepancies highlight the extremely intermittent nature of CMW formation. They are in good agreement with the results of Qu et al. (2002) who found CMW formation to be strongly associated with eddies. These central mode waters could be said not to outcrop in a particular area, but to surface from time to time in a large and ill-defined region of the northwestern North Pacific. The NPTW also has a large number of discrepancies and low number of matches. This may have to do with a general warming of the basin observed in the floats relative to the WOA01 as will be discussed below. We did a basin-wide average and found that, over the entire North Pacific, the floats were warmer than the WOA01 by about $0.5^{\circ} \mathrm{C}$. Most of the discrepancies of the number 2 type were because the observation was warmer than the WOA01.

Because surfacing floats may have properties different from the WOA01, it is worthwhile to examine the medians and standard deviations of T-S properties of floats within a given area. This will tell us if the floats are measuring characteristics very different from the WOA01. This is done in Fig. 2c, where the medians are shown for each water mass with standard deviation bars. These are the medians and standard deviations for all floats surfacing in the area defined for a particular water mass by the WOA01 (gray areas in Fig. 3, cases 2 and 3 in the previous paragraph). The distributions fall well within the range stated in Table 1 for the warmer water masses. The LCMW and DCMW standard deviation bars extend well outside the range, but the medians are inside.

Despite the fact that the various water masses are generally found within the outcrop areas predicted by the WOA01, there is significant T-S variability between the floats and the WOA01. To highlight this point we did the following analysis. For each float that surfaced in a water mass region (gray areas in Fig. 3), we took the difference between the float and the value taken from the WOA01 where the float surfaced. In other words, if the float surfaced and measured a mixed layer temperature of, say, $10^{\circ} \mathrm{C}$, while the value of the WOA01 at the same one degree square was $9^{\circ} \mathrm{C}$, we recorded the temperature difference as $1^{\circ} \mathrm{C}$. A similar analysis was done for salinity. Histograms of those temperature and salinity differences are displayed in Figs. 5a-b.

The temperatures of the various water masses in 2006 are generally biased high, with the floats measuring warmer temperatures than indicated by the WOA01 (Fig. 5a). The DCMW histogram appears closest to being symmetric about zero, but is still biased somewhat warm.

The 2006 salinity histograms are more mixed (Fig. 5b). Two water masses are fresher than indicated by the WOA01 (DCMW and ESTMW) and the rest are saltier.

To put the Fig. 5 results into context we did a similar analysis for the entire North Pacific (Fig. 6). For the temperature, this shows that Argo floats were warmer than climatology over a broad swath of the tropical North Pacific for 2006 (Fig. 6a). The mode water formation areas of the northwestern North Pacific are a special case. There we see a mixture of cold and warm floats, blue and red symbols in close proximity. In this view, it is difficult to see the same trend in temperature in the mode water formation areas that we saw in Fig. 5a. The ESTMW and NPTW areas are more central and clearly warmer than climatology as shown in Figs. 5a and $6 \mathrm{a}$.

For salinity, the North Pacific is fresher than climatology for a large area south of about $25^{\circ} \mathrm{N}$, wrapping around into the northeastern and northwestern basins(Fig. 6b). This matches the freshening of the ESTMW seen in Fig. 5b. An area of the central North Pacific, centered around $30^{\circ} \mathrm{N}$, $160^{\circ} \mathrm{E}$ is saltier than the WOA01. This salinification of the NPSTMW formation area is consistent with curve of Fig. $5 \mathrm{~b}$.

\section{Discussion}

Overall, the WOA01 and 2006 Argo floats show the outcrop areas of some major North Pacific water masses to be very similar, except for the central mode waters (Fig. 3). The volumes of the water masses agree well between the two data sets (Table 1) as do the T-S characteristics (Fig. 2c), again with the exception of the Central Mode waters. 

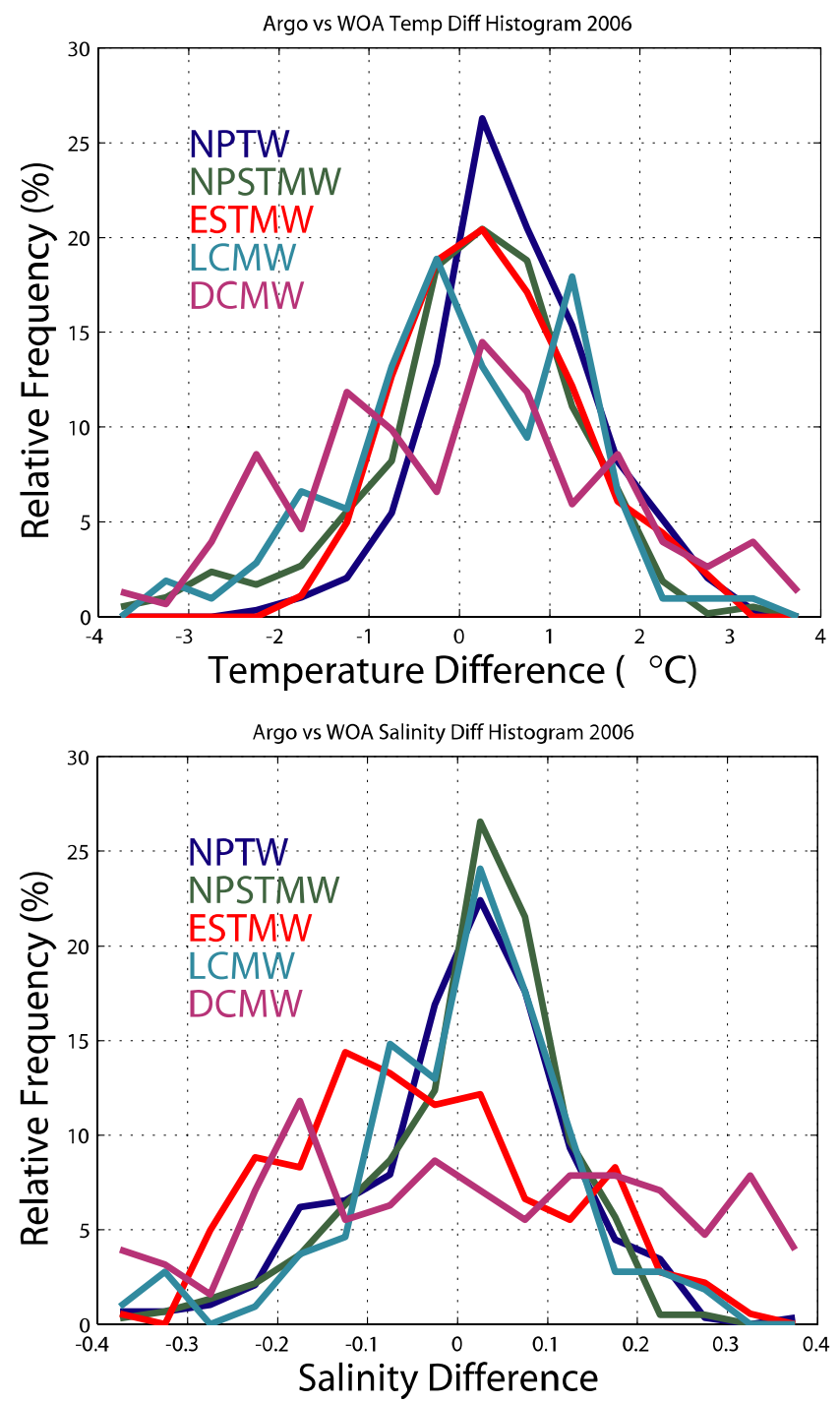

Fig. 5. Histograms of the difference between float measurements and the WOA01 for various named water masses (Table 1). Water masses are indicated by different colored lines, with keys in the figures. Results are presented as relative frequencies summed up within a temperature (salinity) range of $0.5^{\circ} \mathrm{C}(0.05)$. (a) Temperature 2006. (b) Salinity 2006.

Suga et al. (2006) $)^{2}$ computed a subduction transport as a function of temperature and salinity class, similar to Fig. 2a for the WOA01. That is, they calculated the subduction rate at each one degree square, multiplied it by the surface area, and summed the transport up for each T-S class. The result is a calculation of water mass volume subducted in a year. The amount of water subducted in a year in a one degree square should be equal to a fraction of the depth of the late winter mixed layer, multiplied by the surface area. That is, once the winter is over, one would expect some fraction $(1 / 2$ ?, 2/3?)

\footnotetext{
${ }^{2}$ Suga, T., Aoki, Y., Saito, H., and Hanawa, K.: Ventilation of the North Pacific subtropical pycnocline and mode water formation, Prog. Oceanogr., in review, 2006.
}
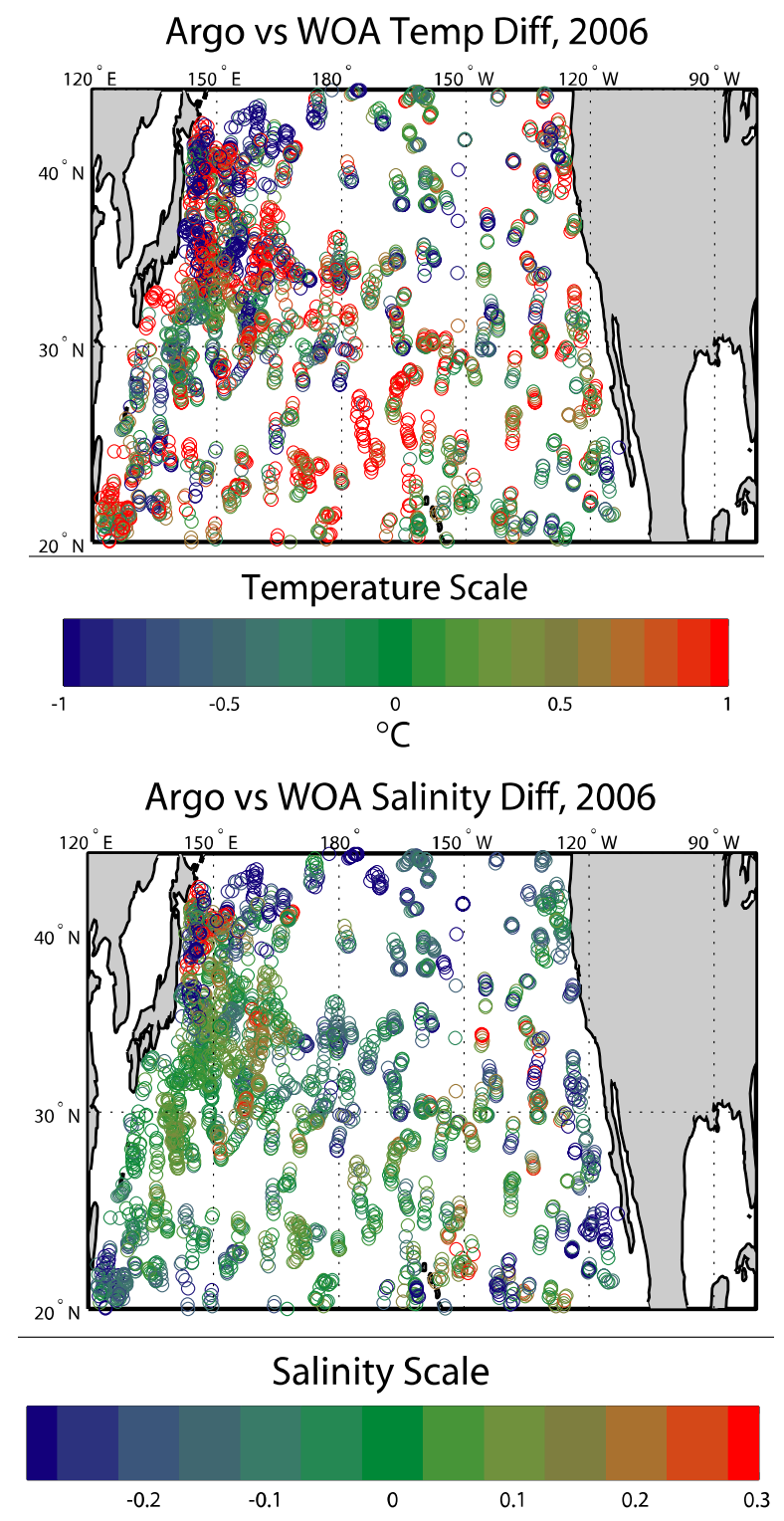

Fig. 6. Difference between Argo float and local WOA01 values at $10 \mathrm{~m}$ depth. (a) 2006 Temperature. (b) 2006 Salinity. At bottom are color scales for $(a-b)$.

of the water in the mixed layer at the end of winter to be inducted into the interior circulation depending on the subduction rate, meridional slope of the mixed layer base, the depth of the spring seasonal thermocline, etc. Comparison of Suga et al.'s $(2006)^{2}$ results and what is presented here is consistent with this expectation. Our water mass volumes are generally larger than their subduction volumes but by less than an order of magnitude. This gives confidence in both the present study and in their more complicated calculation.

The formation of NPSTMW, ESTMW and NPTW is wellrepresented in most eddy-resolving general circulation models (e.g. Tsujino and Yasuda, 2004) but simulating the formation of central mode waters has been more difficult. One 
reason suggested for this is that restoring models to observed SSS and SST is that it double counts the heat and salt transport by western boundary currents and their extensions leading to warm biases in the western and central mode water formation areas (Qu et al., 2002). The present study can give a clue as to why it has been difficult to simulate the formation of central mode waters. The reliance on relaxation back to the WOA01 or other climatology could introduce problems into a model due to the difference between climatological mixed layer and what is actually present. The formation process of central mode waters is fundamentally different from the other water masses discussed here in that it occurs intermittently in space and time (Saito, personal communication). The isopycnals on which these water masses circulate are not open to the atmosphere on a regular basis over a well-defined region like the other water masses studied.

Figure 6 indicates that as a whole in 2006 the North Pacific mixed layer was fresher and warmer than average. These changes encompassed the vast majority of the tropics and eastern and northeastern basins. On the other hand, the mode water formation areas were much less clear as shown in Figs. 5 and 6. This illustrates the fundamentally different nature of surface processes in these areas in winter. Surface properties in the mixed layer are controlled by wintertime heat loss and subsequent convection. The mode water formation areas have a number of fronts within them, which makes the determination of the float sampling a matter of geography. Whether a float measures warmer or cooler (or fresher or saltier) than climatology depends mostly on which side of a local front the float happens to surface on. This makes determination of interannual variability of the T-S properties of mode water formation areas trickier than other regions. Interannual variations may be much more in the nature of shifts in the positions of fronts than changes in T-S properties.

We can only speculate here on the reasons for the T-S differences between WOA01 and Argo shown in Fig. 6. Most likely, they are due to interannual variability. That is, surface waters in 2006 happened to be particularly fresh and warm over much of the North Pacific. Similar results were obtained but not shown for 2004 and 2005. Though this is the obvious explanation, there are others possible. Differences could be a result of spatial or temporal sampling biases in the way the floats surfaced. This is most likely a problem for the DCMW and LCMW formation areas, which were not well-sampled by floats in 2006 (Fig. 3e). Another potential issue is biases introduced into the WOA01 in the smoothing and averaging process. Whatever the reasons for the observed differences, the WOA01 will be used in the future as a benchmark against which changes can be measured.

Acknowledgements. Three anonymous reviewers read the manuscript carefully and gave thoughtful comments. This study could not have happened without the quality-controlled Argo dataset generously provided by E. Oka of JAMSTEC and the University of Tokyo. F. M. Bingham was supported by the $21 \mathrm{st}$ Century COE program "E-ASTEC" at Tohoku University. T. Suga was supported in part by the Japan Society for the Promotion of Science (Grant-in-aid for scientific research (B), No. 16340135) and the Ministry of Education, Culture, Sports, Science, and Technology (Grant-in-aid for exploratory research, No. 17651002). Argo data were collected and made freely available by the International Argo Project and the national programs that contribute to it (http://www.argo.net). Argo is a pilot program of the Global Ocean Observing System.

Edited by: M. Tomczak

\section{References}

Argo Science Team: Argo: The global array of profiling floats, in: Observing the oceans in the 21st Century, edited by: Koblinsky, C. J. and Smith, N. R., GODAE Proj. Off., Melbourne, Australia, 248-258, 2001.

Bingham, F.: The Formation and Spreading of Subtropical Mode Water in the North Pacific, J. Geophys. Res., 97, 11 177-11 189, 1992.

Bingham, F. M., Suga, T., and Hanawa, K.: The Origin of Waters Observed along $137^{\circ}$ E, J. Geophys. Res., 107, C7, doi:10.1029/2000jc000722, 2002.

Boyer T. P., Stephens, C., Antonov, J. I., Conkright, M. E., Locarnini, R. A., O'Brien, T. D., and Garcia, H. E.: World Ocean Atlas 2001: Volume 1: Salinity, 165 pp., National Oceanographic Data Center, Silver Spring, MD, 2002.

Conkright M. E., Locarnini, R. A., Garcia, H. E., O’Brien, T. D., Boyer, T. P., Stephens, C., and Antonov, J. I.: World Ocean Atlas 2001: Objective Analysis, Data Stastics and Figures CD-ROM Documentation, 17 pp., National Oceanographic Data Center, Silver Spring, MD, 2002.

de Boyer Montegut, C., Madec, G., Fischer, A. S., Lazar, A., and Iudicone, D.: Mixed layer depth over the global ocean: An examination of profile data and a profile-based climatology, J. Geophys. Res., 109, C12003, doi:10.1029/2004JC002378, 2004.

Endoh, T., Mitsudera, H., Xie, S., and Qiu, B.: Thermohaline Structure in the Subarctic North Pacific Simulated in a General Circulation Model, J. Phys. Oceanogr., 34, 360-360-371, 2004.

Hanawa, K. and Talley, L. D.: Mode Waters, in: Ocean Circulation and Climate: Observing and modelling the Global Ocean, edited by: Siedler, G., Church, J., and Gould, J., Academic Press, London, 373-386, 2001.

Hautala, S. L. and Roemmich, D. H.: Subtropical mode water in the Northeast Pacific Basin, J. Geophys. Res. (C Oceans), 103(C6), 13 055-13 066, 1998.

Huang, R. and Qiu, B.: Three-Dimensional Structure of the WindDriven Circulation in the Subtropical North Pacific, J. Phys. Oceanogr., 24(7), 1608-1622, 1994.

Iselin, C. O.: The influence of vertical and lateral turbulence on the characteristics of the waters at mid-depths, Trans. Am. Geophys. Union, 20, 414-417, 1939.

Kara, A. B., Rochford, P. A., and Hurlburt, H. E.: An optimal definition for ocean mixed layer depth, J. Geophys. Res. (C Oceans), 105(C7), 16 803-16821, 2000.

Ladd, C. and Thompson, L.: Formation Mechanisms for North Pacific Central and Eastern Subtropical Mode Waters, J. Phys. Oceanogr., 30(5), 868-887, 2000. 
Marshall, J. C., Nurser, A. J. G., and Williams, R. G.: Inferring the Subduction Rate and Period over the North Atlantic, J. Phys. Oceanogr., 23(7), 1315-1329, 1993.

Masuzawa, J.: Subtropical Mode Water, Deep-Sea Res., 16, 463472, 1969.

Miura, T., Suga, T., and Hanawa, K.: Winter Mixed Layer and Formation of Dichothermal Water in the Bering Sea, J. Oceanogr., 58(6), 815-823, 2002.

Ohno, Y., Kabayashi, T., Iwasaka, N., and Suga, T.: The Mixed Layer Depth in the North Pacific as Detected by the Argo Floats, Geophys. Res. Lett., 31, L11306, doi:10.1029/2004GL019576, 2004.

Oka, E. and Suga, T.: Differential Formation and Circulation of North Pacific Central Mode Water, J. Phys. Oceanogr., 35, 19972011, 2005.

Qiu, B. and Huang, R. X.: Ventilation of the North Atlantic and North Pacific: Subduction versus obduction, J. Phys. Oceanogr., 25(10), 2374-2390, 1995.

Qu, T., Xie, S., Mitsudera, H., and Ishida, A.: Subduction of the North Pacific Mode Waters in a Global High-Resolution GCM, J. Phys. Oceanogr., 32(3), 746-763, 2002.

Stephens, C., Antonov, J. I., Boyer, T. P., Conkright, M. E., Locarnini, R. A., O'Brien, T. D., and Garcia, H. E.: World Ocean Atlas 2001: Volume 1: Temperature, 165 pp., National Oceanographic Data Center, Silver Spring, MD, 2002.
Stommel, H.: Determination of water mass properties of water pumped down from the Ekman layer to the geostrophic flow below, Proc. Natl. Acad. Sci. USA, 76(7), 3051-3055, 1979.

Suga, T., Kato, A., and Hanawa, K.: North Pacific Tropical Water: its climatology and temporal changes associated with the climate regime shift in the 1970s, Prog. Oceanogr., 47(2-4), 223-256, 2000.

Suga, T., Motoki, K., Aoki, Y., and Macdonald, A. M.: The North Pacific Climatology of Winter Mixed Layer and Mode Waters, J. Phys. Oceanogr., 34(1), 3-22, 2004.

Sugimoto, S. and Hanawa, K.: Remote reemergence areas of winter sea surface temperature anomalies in the North Pacific, Geophys. Res. Lett., 32, L01606, doi:10.1029/2004GL021410, 2005.

Tsujino, H. and Yasuda, T.: Formation and Circulation of Mode Waters of the North Pacific in a High-Resolution GCM, J. Phys. Oceanogr., 34(2), 399-415, 2004.

Xie, S. P., Kunitani, T., Kubokawa, A., Nonaka, M., and Hosoda, S.: Interdecadal Thermocline Variability in the North Pacific for 1958-1997: A GCM Simulation, J. Phys. Oceanogr., 30, 2798$2813,2000$. 